\title{
Rebecca Baillie
}

\section{Tracey Emin: Ideas of Melancholy and Maternity}

This text introduces a small part of larger project that explores not only the work of the artist Tracey Emin, but also that of other women artists whose work is considered in relation to ideas of melancholy and maternity. The project as a whole endeavours to understand the idea of melancholy, suggested by psychoanalyst Julia Kristeva as one that is irreducible to its verbal or semiological expressions'. ${ }^{1}$ I argue that it is necessary to discuss the term not only alongside feminism, psychoanalysis and ideas of maternity, but also to scrutinize its visual depiction. Very generally put, the melancholic female artist is fixated on a lost ideal - on the umbilical connection she once had with her mother, and subsequently, on other intimate but unsustainable relationships. Refusing to sever attachments to the lost object, the melancholic artist instead becomes haunted by it. Robert Burton, the seventeenth century English scholar, crucial to any discussion of melancholy, endeavoured to present the condition 'philosophically, medicinally and historically opened and cut up'. However, in his refusal to acknowledge the melancholy female, and also in only looking briefly at images, he failed to fully dissect the melancholy state. ${ }^{2}$ Often posing as a maternal subject, Tracey Emin reveals that feelings of loss remain bound neither to an unconscious psychological concept nor woven only in the past and only to our mothers. I argue that a woman's experience or fantasy of maternity is important to consider as a surrogate relationship created to alleviate the pain of melancholy in response to the original separation experienced between mother and child. ${ }^{3}$

\section{Maternal Fantasy}

Although not a mother, Tracey Emin is fascinated by pregnancy and ideas of the maternal. Indeed, it was the artist's relationship with ideas of maternity that emerged as the most pertinent theme of her 2009 exhibition, Those who suffer Love. ${ }^{4}$ One of the works on display was a monoprint diary made in 1991; the work consists of 24 blue line drawings, many of which depict the artist's body in an imaginary state of pregnancy. In one particular image, the outline of a woman's body stands facing the viewer with a foetus in utero: the text beside the image reads, 'Is this me?'. Produced at a time close to one of her abortions, Emin simultaneously fantasizes about the experience of pregnancy, and asks herself if she would be able to live with the reality of a pregnancy developing. ${ }^{5}$ Other works in Those who suffer Love include a

Rebecca Baillie, Tracey Emin: Ideas of Melancholy and Maternity

Studies in the Maternal, 3(1), 2011, www.mamsie.bbk.ac.uk 
selection of embroidery pieces made in 2007 which also illustrate the artist carrying a child. One of these works, Power Line, forges a subtle link with the idea of a life-giving umbilical cord. In Insane Reflection, by contrast, Emin is obviously pregnant, kneeling to the side with her hands shielding a large pregnant belly: a fantasy of maternity. This fantasy is exercised to such a degree, that in a work called Feeling Pregnant, Emin exhibits a complete collection of crocheted baby clothes that she made while waiting for her period. The artist constantly uses childlessness as a major source of inspiration for her artwork; it is as if she recognises that the mother-child relationship - and perhaps even more so the imaginary version of this bond - is another possibility, apart from an erotic love connection that allows for the assuaging of melancholy through a newly created physically co-dependent state. ${ }^{6}$

In Approaching Sacred Pregnancy, Ira Westergard explains how some late medieval female mystics experienced what have been described as mystical pregnancies. ${ }^{7}$ She writes that:

...these visions were especially frequent during advent, perhaps inspired by the forthcoming celebration of the Birth of Christ. During an exalted moment of joy the mystic would feel as if she were literally carrying the baby Jesus in her body, feeling his movements and giving birth to him. ${ }^{8}$

Westergard also explains that although fourteenth-century mystics, such as St. Birgitta of Sweden and Dorothea of Montau were themselves mothers, the mystical pregnancy they experienced was overwhelmingly more powerful than any ordinary pregnancy. I consider this idea in reference to the work of Tracey Emin and suggest that the fantasy of maternity that she depicts is more consuming than the actuality of the experience. Could we argue that the reality of the maternal experience is more difficult to articulate for women, and that in some ways the fantasy - an imagining of birth-giving and being with child - raises more interesting questions and concerns than the reality?

Paula Modersohn-Becker, a German artist working during the early twentieth century depicted herself pregnant a year before she in fact conceived her daughter. In Self Portrait on her Sixth Wedding Day, painted in 1906, Modersohn-Becker confronts the viewer with a penetrating outward stare as she reveals her own body, naked from the waist up, and pregnant. Here the fantasy of being pregnant acts as preparation for the oncoming actual experience. In the painting, Modersohn-Becker lovingly cradles her swollen belly and therefore conveys not only her personal desire for a child but also the more general view that

\section{Rebecca Baillie, Tracey Emin: Ideas of Melancholy and Maternity}

Studies in the Maternal, 3(1), 2011, www.mamsie.bbk.ac.uk 
the female body acts as a symbol for the continuing source of life. In a letter written to her husband, Otto, in February 1903, Modersohn-Becker explains that she thinks of her own nakedness as a metaphor for honesty and openness; this is a viewpoint that Tracey Emin shares, and one that continued to manifest itself in other self portraits by Modersohn-Becker. At the time that Paula Modersohn-Becker created this work it was particularly revolutionary. It was not usual for women to depict themselves naked, and certainly not naked and pregnant.

Indeed, historically, biological processes and bodily functions have been censured from the representation of the female nude. As Lennard Davis reminds us in 'Nude Venuses, Medusa's Body, and Phantom Limbs', 'there are no pregnant Venuses and there are no paintings of Venuses who are menstruating, micturating, defecating - lactating and lacrimating are the only recognised activities of idealized women'. 'Therefore, an investigation into pregnancy in art is a relatively recent development, only embarked upon as women have become the active subjects of their own work. In Mother Figures, Rosemary Betterton discusses the work of Paula Modersohn-Becker and refers to motherhood as a 'state of physical absorption and psychic possession' that disturbs our preconceptions in relation to the body. ${ }^{10}$ The state is indeed one of absorption and one that explicitly recalls the past umbilical connection to one's own mother. On the one hand, images of pregnancy invoke feelings of comfort as the viewer is reminded of a once highly efficient co-dependency; on the other hand, however, they conjure feelings of loss, a realisation that being inside the womb is a state to which we cannot return. Therefore, Self Portrait on her Sixth Wedding Day not only conveys the circular nature of life, but also the continuous cycle of longing for a union experienced in the past.

Unlike the work of Modersohn-Becker, where the fantasy of maternity was created before a subsequent birth, Emin revisits actual pregnancies after these have been terminated. Therefore, although Emin has never become a mother, she has experienced the occupation of her body by another life. She acknowledges the power of the female ability to reproduce and constantly revisits this idea in her work. The artist has aborted two pregnancies and much of her work seems to be created in mourning of this experience. In 2002 Emin produced a blanket called I do not expect, on which she appliquéd the words: 'I do not expect to be a mother, but I do expect to die alone'. Even a decade after a decision made not to have

\section{Rebecca Baillie, Tracey Emin: Ideas of Melancholy and Maternity}

Studies in the Maternal, 3(1), 2011, www.mamsie.bbk.ac.uk 
children, Emin continues to consider the importance and meaning of motherhood. In The Interview with herself in 1999, when thinking on the subject of children, she says, ' "I'm not evading the truth. I'm telling you, I think about it. I think about it a lot because I'm 35 years old". "You're drying up". I'm not drying up. My womb is drying up.' "11 Furthermore, in an interview with the artist's mother in 2001, the two women discuss the unusual way that Emin was raised, including her mother putting her on the pill at age 13 so as not to get pregnant. The artist's mother expresses her opinion that her daughter should never have children. Emin's mother sees being with child not as a restorative union, but instead as a burden and a frustration. She insists that Emin is a free spirit and in order to stay that way she must not have children. ${ }^{2}$ The implication here is the reality of motherhood and of day-to-day care leaves little opportunity for philosophical reflection on what it means to exist in duality or codependency. Whereas the fantasy of maternity has the power to alleviate feelings of melancholy by implying that beings need not exist alone, the reality of becoming a mother highlights the painful inevitability of separation resulting from the child's early drive for independence.

\begin{abstract}
Abortion
Preventing the fantasy of maternity from ever becoming a reality, Tracey Emin has had two abortions. The literature on this part of the artist's life can be quite confusing, probably because she had two terminations close to one another. CV Cunt Vernacular of 1997 is the best reference to get accurate information on the subject. In 1990, Emin writes 'Became Pregnant - had an abortion. It went wrong. Caught the foetus - slipping down my thigh cried and cried,. ${ }^{13}$ In 1992 she writes, 'Became pregnant again - had another abortion - didn't give a damn. Just did it - dealt with it without heart'. In the middle of 1992, she informs her audience that she 'committed emotional suicide', she broke off all friendships and sexual relationships and destroyed all of her work. ${ }^{14}$ The discrepancy in material comes when we watch the documentary film piece called How it feels that Emin made in 1996 as a detailed descriptive account of her first abortion that happened in 1990. Emin says in this work that she had her 'emotional suicide' and her giving up of painting and people. However we know from Cunt Vernacular that this did not actually happen until 1992 and it seems therefore that the artist has created a kind of real/fictitious amalgamation of both of her abortion experiences in one work.
\end{abstract}

Rebecca Baillie, Tracey Emin: Ideas of Melancholy and Maternity

Studies in the Maternal, 3(1), 2011, www.mamsie.bbk.ac.uk 
How it feels is a diary style documentary, in which the camera follows Emin on a trail around London as she goes from a spot outside her doctor's surgery where her doctor advised strongly against the abortion, to a park where a tree has grown over the six intervening years, and then to outside the abortion clinic where the procedure took place. Emin explains in the video that her doctor had previously told her that there was a $99.9 \%$ chance that she could never have children. In 1990 therefore, the doctor tried to push Emin to go through with the pregnancy perhaps because it was almost a miracle that she had conceived at all. It was because of the doctor's hesitation in supporting Emin's decision to have an abortion that she ended up being three and half months pregnant before the operation took place. In fact, even when Emin had her first abortion, it did not work properly, her womb became infected and the damaged foetus actually came out of her body days later, falling into her own hands. This experience was profoundly traumatic and the artist communicates the extreme upset that she still holds inside on film. Emin says, 'I'm angry actually, which is why it is quite hard for me to talk, I'm really angry about it. I didn't think coming back here would make me so angry, I thought I'd probably be able to act or do something. I thought that I might even be able to smile and say I've got over this, but no I haven't. I don't think I will ever really get over it. ${ }^{, 15}$

At the time of the traumatic, messy abortion, Emin made a series of colourful paintings on sheets of lined paper. The brushstrokes of these works bleed into the paper and we can usually make out a female figure inhabited by a blobby red foetus somewhere in the primary colour mark making. The other symbol that is recognizable in these childlike or Neolithic pattern-scapes, is the heart. Emin exhibited these paintings, along with other memorabilia from the abortion and a piece of monoprint text. The text reads very poetically, like a love poem: 'Forgive me tiny little thing. Your soul is free. Forgive me - Leave me-... I cradled a foetus closely between my palm and my thigh. Knowing it had never wanted to leave me.' Emin continues in a similar tone of romantic mourning in How it feels: 'It's like I tried to explain earlier, it's like my eyes, something in my eyes has changed. It's like, it's like the branches in a tree in winter and they never blossom and they never have leaves ever again, but the tree is still alive. That's what my eyes are like and that's what happens when you have a broken heart. I am scarred. My eyes are scarred because of what I have witnessed which I was so physically part of. ${ }^{16}$ As already suggested, Emin explains that in a similar way to losing a lover, the loss of her child has broken her heart. As another means of severing co-

\section{Rebecca Baillie, Tracey Emin: Ideas of Melancholy and Maternity}

Studies in the Maternal, 3(1), 2011, www.mamsie.bbk.ac.uk 
dependency - related to that of initial separation from mother's body - abortion highlights melancholy and the impossibility of recreating satisfaction in duality. As the melancholic strives to recreate a perfect umbilical connection, abortion forcibly acknowledges that lifelines are inevitably cut.

Despite the sorrowful nature of Emin's decision made in 1990, she also makes clear that the death of this foetus generated new life in her art. Similarly, in Frida Kahlo's drawing of her miscarriage in 1932, it is the half of Kahlo that bleeds and loses her baby that holds the painting palette and fertilises the earth. The half of the body that retains the child stands as a mother and not as an artist. For Emin, the loss of her child became the necessary catalyst to change her art into a vital practice that engaged with everyday experience. In the voiceover of How does it feel, she says, 'I realised that if I was going to make art it couldn't be about... it couldn't be about a fucking picture. It couldn't be about something visual. It had to be about where it was really coming from and because of the abortion and because of conceiving, I had a greater understanding of where things really came from'. ${ }^{17}$ By the time Emin had her second abortion in 1992, she made the decision to destroy all the work she had made at the Royal Collage of Art, understanding that art for her did not rest in painting traditional historical or religious scenes. For Emin, the bodily aspect of having had an abortion from this point onwards became crucial to her work. In an interview with Carl Freedman called 'Break through onto the other side', Emin recalls the work of American artist, Kiki Smith, when she answers one question, 'There's something in me which is too much and it's always coming out. ${ }^{18}$ She goes on to reveal her need for connections, as she talks of her fingers as 'these spindly things always coming out like that, and I always have to attach them to some thing. ${ }^{19}$ In response to her second abortion, Emin made a series of monoprints in 1995 in which she lies on a hospital bed in a similar state of pain and despondency as Frida Kahlo in 1932 Henry Ford Hospital. Notably in the painting by Kahlo, connective red ribbon ties emerge from the artist's fingers and link to various symbols.

Here it is worth mentioning the work of another important woman painter, Alice Neel. Neel, like Emin, deals with the contradiction in both longing for and rejecting maternity. In Well Baby Clinic, a painting of 1928-29, Alice Neel presents a very menacing and depressive vision of child-care and the mother and child relationship, as we witness a scene of screaming newborns in a deprived and crowded hospital. Neel's first daughter, Santillana died

\section{Rebecca Baillie, Tracey Emin: Ideas of Melancholy and Maternity}

Studies in the Maternal, 3(1), 2011, www.mamsie.bbk.ac.uk 
of diphtheria at the age of one in 1928, and in 1930, her husband took her two-year old second daughter with him back to Cuba. After the loss of Isabetta, Neel painted Futility of Effort the painting is very somber in palette and depicts a baby dressed in white - floating in the middle of an otherwise almost empty grey canvas - as if hanging from a hospital bedstead and we are not sure if she is dead or alive. In this work, Neel at once mourns the actual death of Santillana and the loss felt having been parted from Isabetta. In 1933 the artist painted Symbols, which depicts a child that looks like a voodoo doll encircled by three apples, a black cross and a single red glove. The image evokes the ritualistic sacrifice and martydom that Alice Neel associated with childbirth. Despite her own ambivalent feelings towards motherhood, in the mid-1960s Neel's interest in the subject of maternity was reinvigorated by the pregnancies of her daughters-in-law. At a point when her own body was unable to reproduce, the artist remained fascinated by the psychological power of pregnancy and the importance of this state in understanding female identity, perhaps even more so at a time when she was not immediately and intensely involved with these ideas.

\section{Melancholy}

There is one work in which Emin unites the ideas of melancholy and maternity in a particularly powerful way. The work is called Homage to Edvard Munch and all My Dead Children, a one minute video shot on Super 8 film. The video frames the end of a Norwegian pier. Tracey Emin is curled up in a fetal position at the end of the pier surrounded by rippling waters. There is at once the sense that the womb-like waters provide the artist with protection and at the same time are ready to consume and reclaim her at any moment. The location chosen by Emin is the very same location that Edvard Munch used to paint his iconic image, The Scream in 1893. In an essay from 2005, 'Tracey Emin: A Particular Honesty', Rudi Fuchs begins by explaining that this particular image by the Norwegian expressionist is in fact her favourite historical painting. Due to the fact that Emin actually screams in this piece - a long, piercing and painful scream - Fuch's suggests that the version by this artist is more of a realistic depiction of anguish, whilst the one by Munch is more symbolic. ${ }^{20} \mathrm{I}$ suggest that the emotion displayed here is that of melancholy, and whilst it is entirely left to the imagination what the figure in Munch's painting is screaming about, in Tracey Emin's video, she tells us that she is mourning artists from the past and all of her dead children: she remains articulate despite being consumed by a melancholy longing as she suffers, isolated and alone.

\section{Rebecca Baillie, Tracey Emin: Ideas of Melancholy and Maternity}

Studies in the Maternal, 3(1), 2011, www.mamsie.bbk.ac.uk 
Therefore, while Lorna Healy suggests in her chapter on Emin in the anthology of collected essays, The Art of Tracey Emin, that Homage to Edvard Munch is a statement of allegiance to an established art tradition, and that 'the scream is commonly understood as the essential Expressionist gesture: the barely articulate, violent externalisation of psychic pain', she highlights the fact that what Emin is doing is something quite different. ${ }^{21} \mathrm{I}$ disagree with Healy as she presents Emin's affiliation with Expressionism as a negative one, due to the fact that expressionist artists were known for primitivising women and non-Westerners. I suggest, in contrast to Healy, that it is Emin's love of artists like Vincent Van Gogh, Edvard Munch and Egon Schiele that nourishes rather than diminishes what is most radical and original about her work. ${ }^{22}$ For, of course, the aspect of Expressionism that Healy neglects, and which Emin is seduced by, is melancholy. While the male expressionists retain an atmosphere of irreducible sadness in their works, Emin by contrast, gives us the extra information necessary to investigate where this mood originates. Rudi Fuchs insightfully poses the question as to whether indeed the figure in Munch's painting is a man or a woman. He reads the 'particular honesty' of Emin's interpretation of The Scream as more revealing and realistic, coming from a way of 'storytelling that is typically female. ${ }^{23}$

In the same anthology of collected essays on Emin's work, Chris Townsend focuses on the influence of the Austrian painter, Egon Schiele on the work of Emin. It is interesting to note that Chris Townsend is also a principal writer on Francesca Woodman and in the title of his chapter, 'Heart of Glass', he already hints at the idea of melancholy. By using the word 'Heart', Townsend recalls all of the yearning for romantic love - a substitute for original loss - also thoroughly investigated in Emin's œuvre. By suggesting that Emin's heart is made of the delicate material glass, he conjures the words of Samuel Butler, an English man who wrote about a melancholy character in the seventeenth century: 'his brain is so cracked that he fancies himself to be glass, and fears that everything that everything he comes near should break him in pieces. ${ }^{24}$ Townsend interprets the work of Emin as a critical, ethical response to Egon Schiele's voyeuristic way of representing the sexualised and hysterical female object. For Townsend, Emin appropriates and at the same time, inverts the traditional way of looking that Schiele represents. The Life Model Goes Mad is the title of a series of photographic stills produced to document the three-week period that Emin spent incarcerated in a Swedish gallery in 1996. Throughout this time, the public could observe Emin at any point during gallery hours: she was usually naked, painting, drawing and thinking. Here the model is at

\section{Rebecca Baillie, Tracey Emin: Ideas of Melancholy and Maternity}

Studies in the Maternal, 3(1), 2011, www.mamsie.bbk.ac.uk 
once subject and object of her work, she is an artist with her own voice and is in no sense dominated by the male gaze. Townsend suggests that the artist becomes a genderless subject, enlightened by the discovery that femininity, like masculinity is only ever performed. ${ }^{25}$ To make such a suggestion, however, is to deny the body and is therefore the antithesis of what both the artwork of Tracey Emin and Egon Schiele is about.

Along with other male expressionists, namely Edvard Munch, Schiele moves closer to a more honest and revealing depiction of the human condition and the temperament of melancholy. Indeed, it is from a point of similarity rather than difference that Emin is attracted to the work of Schiele. Stylistically, the younger artist clearly admires Schiele's drawing technique and the single sparse line of her monoprints often bears strong resemblance to his heavy pencil marks. Both artists are wholly preoccupied with selfportraiture, and therefore with the question 'who am I?'. Unlike other early twentieth century male expressionists, Schiele is obsessed with his own self-image and not only that, but with his own image doubled and split and also in relation to the body of a woman. I interpret his Self-portrait Drawing a Nude Model in Front of a Mirror, 1910, as a signal that he recognizes the importance of women in a quest of self. Like Emin, he feels the pull of an earlier sensory state of co-dependent being. In attempts to revive this earlier ideal experience he depicts himself with lovers and as part of a family, with a child. In melancholy awareness of isolation, Schiele, very unusually for a male artist, painted himself giving birth to himself. The work is called The Birth of a Genius (Dead Mother II) 1911 and it shows the artist himself, with a womb, with a baby self inside. Schiele understands that melancholy results from the yearning for the mother's womb and that to be able to live healthily alongside melancholy and not be overwhelmed by the idea, one must progress: one must sever this original co-dependency as much as possible, endeavor to make new unions and ultimately come to terms with the idea that the most satisfying relationship outside of the womb is found with a single self.

Returning to Homage to Edvard Munch and all of My Dead Children, it is particularly interesting that Emin gives an artist from the past the same position of importance as a child that she has aborted. This suggests that there is another way that artists reveal their temperaments as melancholy. Endeavouring to keep melancholy under control, they make connections with other artists, regardless of whether they are dead or alive. Knowledge of art history is therefore crucial to Tracey Emin. She not only feels profound connections with

\section{Rebecca Baillie, Tracey Emin: Ideas of Melancholy and Maternity}

Studies in the Maternal, 3(1), 2011, www.mamsie.bbk.ac.uk 
Egon Schiele, Edvard Munch and Kathe Kollwitz, but also with other artists whose emotions are, like hers, uncensored. Emin has not only dressed up as Frida Kahlo, but she has remarked about the artist:

Her work is completely resolved. You don't look at the paintings and think: I wonder where this is going. Women can relate to her. She did images of herself bleeding in the bath, of foetuses coming out of her and pictures of family and lovers. $^{26}$

More recently, Emin has completed a series of works, Do Not Abandon Me, in collaboration with the late artist Louise Bourgeois. All of these works consist of a male or female torso, printed by Bourgeois, and then overlaid with line drawings and text by Emin. Typical additions by Emin include wombs and foetuses; sometimes empty wombs and often foetuses outside of the female torsos, rather than safely inside. Not only do both artists consider differing relationships between the mother and child, but in striving for artistic dialogue through the physical exchange and co-creation of art pieces, they also reveal a further attempt to coexist as likeminded artists. Therefore, the relationship between Louise Bourgeois and Tracey Emin provides yet another connective challenge to the isolation of melancholy.

As an over-identification with impossible permanent physical co-dependency once experienced in the womb, melancholy can be experienced by both men and women. The work of Tracey Emin reveals that the feeling of loss is not only an unconscious psychological concept and is not only connected to the lost object of the mother. Melancholy yearnings are instead shown to extend outwards to other relationships and both men and women attempt to alleviate the pain of melancholy by creating many different links and connections with other living beings. This said, male artists have a tendency to uphold a certain muteness and opacity surrounding the idea of melancholy. ${ }^{27}$ It is women artists who, in moving away from the isolated melancholy figure and towards the relationship with others, truly open up the subject for dissection. ${ }^{28}$ Women artists often depict themselves with their mothers, with children and with lovers. The potential/experience of becoming pregnant and birthing a child often inspires an obsessive focus of the female artist on her own body, either through visualisation of the body's interior or through repetitive self portraiture. ${ }^{29}$ The work of women artists, and specifically that of Tracey Emin, suggests not only a melancholy mood, but also a related physical affliction, one that has a physical cause, and physical reminders. ${ }^{30}$ As a childless mother, Emin expands our notion of traditional maternal subjectivities,

\section{Rebecca Baillie, Tracey Emin: Ideas of Melancholy and Maternity}

Studies in the Maternal, 3(1), 2011, www.mamsie.bbk.ac.uk 
revealing that the desired state of co-dependency exists in fantasy as well as in reality. As an artist too, she shows that maternal feelings are created between fellow artists and between artist and artwork, in much the same way as they are between the 'real' mother and child. Arguably, there is an intensity and complexity to both melancholy and maternity that is articulated more effectively through images rather than words.

${ }^{1}$ Julia Kristeva, Black Sun: Depression and Melancholia (New York: Columbia University Press, 1989), p.21.

${ }^{2}$ Robert Burton, The Anatomy of Melancholy (London: Chatto and Windus, 1898), writing at the centre of frontispiece.

${ }^{3} \mathrm{I}$ am indebted to the theories of Julia Kristeva when linking the state of melancholy to the original separation between mother and child. However, in my proposal that the fantasy of maternity alleviates melancholy longing, this is entirely original thinking.

4 Those who suffer Love was held at White Cube, Mason's Yard, 29 May - 4 July, 2009.

${ }^{5}$ I have used the term 'abortion' rather than 'termination' in this paper, as this is the term that Emin herself uses.

${ }^{6}$ Influenced by the writings of Julia Kristeva, I refer to 'melancholy' here as a feeling of longing for the lost bodily connection with the mother's body.

${ }^{7}$ Ira Westergard, Approaching Sacred Pregnancy: the cult of Visitation and narrative alterpieces in late fifteenth-century Florence (Helsinki: Suomalaisen Kirjallisuuden Seeura, 2007).

${ }^{8}$ Westergard, p.49.

${ }^{9}$ Lennard Davis, ‘Nude Venuses, Medusa’s Body and Phantom Limbs’ from The Body and Physical Difference:

Discourse of Disability by David T Mitchell and Sharon L Snyder (eds.)(Ann Arbor: University of Michigan Press, 1997), p.58.

${ }^{10}$ Rosemary Betterton, An Intimate Distance: Women, artists and the body (London and New York: Routledge, 1996), p.20.

${ }^{11}$ Emin's Mother in Carl Freedman, Tracey Emin Works 1963-2006 (New York: Rizzoli, 2006), p.39.

12 Emin's Mother in Freedman, p.309.

${ }^{13}$ Emin in Neil Brown, TE: Tracey Emin (Modern Artist series) (London: Tate Publishing, 2006), p.94.

\section{Rebecca Baillie, Tracey Emin: Ideas of Melancholy and Maternity}

Studies in the Maternal, 3(1), 2011, www.mamsie.bbk.ac.uk 
${ }^{14}$ Emin in Brown, p.94.

${ }^{15}$ Emin in Freedman, p.63.

${ }^{16}$ Emin in Freedman, p.63.

${ }^{17}$ Emin in Freedman, p.67.

18 Many of Kiki Smith's sculptures depict female bodies physically leaking from every orifice. For example, Pee Body leaks urine and Train leaks blood.

${ }^{19}$ Emin in Freedman, p.256.

${ }^{20}$ Rudi Fuchs in Freedman, p.391.

${ }^{21}$ Lorna Healy in Mandy Merck and Chris Townsend (eds.) The Art of Tracey Emin (London: Thames \& Hudson, 2002), p.166.

${ }^{22}$ Healy in Merck and Townsend, p.166.

${ }^{23}$ Fuchs in Freedman, p.395.

${ }^{24}$ Samuel Butler in Jennifer Radden, The Nature of Melancholy: from Aristotle to Kristeva (Oxford: Oxford University Press, 2000), p.158.

${ }^{25}$ Merck and Townsend, p.101.

26 Tracey Emin, Tate Etc, Summer 2005, p.58.

${ }^{27}$ Ron Mueck would be a good example of a male contemporary artist who deals with the notion of melancholy, but in doing so maintains a sense of isolation and inaccessibility around the idea. There are of course exceptions to my distinction here and I am aware that some male artists look to their own body and to a dissection of such to further consider melancholy. This, however, is much less typical than in the work of women, who often resolutely only work from their own body and do not stray from this subject for the entirety of their careers. ${ }^{28}$ By 'connection with others' here, I also take this to mean the artist's relationship with her own reflected self.

${ }^{29}$ In the wider project connected to this shorter piece, I consider the work of Kiki Smith and Klara Kristalova who focus mainly on the body's interior, Francesca Woodman and Elina Brotherus who work with repetitive self portraiture and Frida Kahlo, Tracey Emin and Charlotte Lindsay who I suggest do both.

30 The cause of melancholy is the initial separation experienced from the mother's body and reminders of this take the form of watching lovers leave and children grow up.

Rebecca Baillie, Tracey Emin: Ideas of Melancholy and Maternity

Studies in the Maternal, 3(1), 2011, www.mamsie.bbk.ac.uk 